\title{
Calendar effects in Latin American stock markets
}

\author{
Diego Winkelried ${ }^{\dagger}$ \\ Universidad del Pacífico (Lima, Perú)
}

\author{
Luis Antonio Iberico \\ Universidad del Pacífico (Lima, Perú)
}

This version: November 6, 2015

\begin{abstract}
One of the most well-documented empirical regularities in international finance is the presence of calendar effects in historical stock returns. The literature focuses mainly on developed countries and in general emerging markets have not received much attention on this issue. We aim to bridge this gap by documenting the existence of significant and robust calendar effects for the main stock markets in Latin America. Upon performing an extreme bounds analysis that adjusts our estimations for model uncertainty, we find a significantly negative Monday effect, generally compensated by a significantly positive Friday effect. These effects are robust to model specification and are stable through time. Even though not as widespread, we also find evidence for a robust turn-of-the-month effect.
\end{abstract}

$\begin{array}{lll}\text { JEL Classification } & \text { : } & \text { C50, G10, G14, G15 } \\ \text { Keywords } & : & \text { Monday effect, effect coding, extreme bounds analysis, Latin America. }\end{array}$

\footnotetext{
${ }^{*}$ We thank Mauricio Barriga for valuable research assistance and insight. We are also indebted to Alejandro Sancho, Mauricio Zevallos and seminar participants at the XXXIII Economists Meeting of the Central Reserve Bank of Peru for useful comments. We alone are responsible for the views expressed and for any errors that may remain in this paper.

${ }^{\dagger}$ Corresponding author. Academic Department of Finance, Universidad del Pacífico, Av. Salaverry 2020, Lima 11, Peru. Phone: (+511) 2190100 ext. 2238. E-mail: winkelried_dm@up.edu.pe
} 


\section{Introduction}

One of the most well-documented findings in empirical finance is the presence of calendar effects in historical stock returns. Calendar effects refer to the tendency of stock prices to rise or fall in a systematic fashion at a particular, predictable time. Leading examples include effects in different days of the week (such as the Monday and Friday effects), induced by holidays, in different months (such as the January effect), and by the turn of the month or the turn of the year. Among many others, Thaler (1987) and Schwert (2003) provide comprehensive surveys.

The Efficient Market Hypothesis suggests that such widely known, persistent and predictable patterns in the behavior of stock prices should be already internalized and incorporated in these very prices, and hence should not exist. Yet, the evidence of these effects is pervasive at both individual and aggregate levels, among markets throughout the world and through time. Hence, calendar effects are often viewed either as anomalies that do not correspond to the predictions of the Efficient Market Hypothesis, or as clear-cut evidence against such theory. Regardless on whether calendar effects reflect the evolution of fundamentals or not, their regularities are likely to have an impact on the psychological outlook of market participants, eventually helping or harming returns.

The literature has focused mainly on developed countries. Emerging markets have received relatively little attention, and in particular there are scant related studies for Latin America (Kristjanpoller, 2012, is a remarkable exception). We aim to help bridging this gap, and the purpose of this paper is to investigate whether calendar effects are present in the six largest Latin American stock markets (namely, Argentina, Brazil, Chile, Colombia, Mexico and Peru), which as a group represents an important segment of emerging markets. Even though market capitalization in Latin America remains well below industrial countries averages, it has experienced considerably higher growth rates in the 1990s and especially the 2000s, despite a number of economic crises that have struck the region over these periods.

Besides, it has been argued that the evidence for calendar effects may be merely an artifact resulting from a cumulative, and possibly unintentional, "mining" or "snooping" of the data, in particular in the US and other developed markets (cf. Sullivan et. al., 2001; Schwert, 2003). A response to this critique is that calendar effects are likely to be legitimate if also found on an independent dataset, not affected by previous data mining practices (see, inter alia, Agrawal and Tandon, 1994). In this sense, focusing on the relatively unexplored Latin American case gives us the opportunity to assess the validity of calendar effects in stock markets from a more general perspective.

Calendar effects are often estimated within a regression framework. A significant lesson learnt from previous work (see, inter alia, Connolly, 1989; Chang et. al., 1993) is that the conclusions regarding the existence of these effects may depend on the specification of the regression model. Hence, it seems crucial to perform sensitivity analyses and adjust the main inferences by accounting for model uncertainty. To assess the robustness of our empirical findings, we perform an extreme bounds analysis, as advanced in Leamer (1983, 1985). The idea is to construct a corrected confidence interval by selecting the extreme confidence limits from a number of competing return equations, featuring different conditioning factors. Although the method is regarded as being too stringent, we are able to find robust calendar effects in all the countries in our sample. The most important result is, admittedly, the presence of a strong negative Monday effect, generally compensated by an important positive Friday effect. We also find evidence of a robust turn-of-the-month effect.

Besides our empirical findings, we also present a short discussion on model specification. Calendar effects are usually computed as the estimated coefficients in a regression of the historical returns on a set of dummy variables indicating the day of the week, the month of the year, and so on. The coding of such dummy variables affects directly the interpretation attached to the estimated coefficients. Very often, the effects are relative to a reference date, which is necessarily an arbitrary choice of the researcher. We propose to set the reference date to an average date, which we reckon is a natural choice rendering neat effects to interpret. 
The rest of the paper is organized as follows. Section 2 presents a brief review of the literature. Section 3 presents the econometric framework. In particular, it discusses the differences between the so-called "dummy coding" approach versus "effect coding", and its importance to correctly interpret calendar effects. Then, the section describes the extreme bounds analysis and further econometric issues. Section 4 describes the data used in our empirical work, and presents the main results of our investigation. Several sensitivity analyses are conducted and it is concluded that some calendar effects are a robust feature of the data. Section 5 concludes and gives some avenues for future research.

\section{Literature review}

Since the publication of seminal contributions in the early 80s, for instance French (1980) and Gibbons and Hess (1981), the so-called Monday and Friday effects, or simply the "Weekend effect", have received a great deal of attention among academics and market participants. These effects refer to the tendency of stock returns to be significantly higher on the last trading day of the week (usually Friday), and significantly lower, even negative, on the first trading day (Monday). Keim and Stambaugh (1984) find such effects on the US stock market, whereas Lakonishok and Smidt (1988) provide further evidence using almost a century of historical data. Moreover, the Monday and Friday effects have also been documented on different stock markets worldwide. Relevant related work include Jaffe and Westerfield (1985), Chang et. al. (1993), Agrawal and Tandon (1994) and, more recently, Kiymaz and Berument (2003) and Dicle and Levendis (2014). Kristjanpoller (2012) is the only work we are aware of that considers Latin America exclusively.

Diverse theories have been entertained to explain this empirical regularity. For instance, Lakonishok and Levi (1982) point out to settlement and clearing delays in the US stock market. Settlements on stocks take place 5 business days after the payment, whereas clearing via the US Federal Reserve System takes one extra business day. This sums up 8 calendar days ( 6 business days plus a weekend) for every day except Fridays which sum up 10 calendar days (6 business days plus two weekends). Since there are no interest gains on these 2 extra calendar days, the seller of the stocks will demand a higher price, hence the equilibrium expected rate of return on Friday should be higher. A similar accounting is expected to apply on trades before a holiday. Lakonishok and Levi (1982), Lakonishok and Smidt (1988) and Cadsby and Ratner (1992) provide evidence on this.

On the other hand, Foster and Viswanathan (1990) suggest a microstructure model of the stock market resulting from the interaction of three kind of traders: informed traders, liquidity traders and market traders. Informed traders have privileged information on Mondays, so the other two avoid trading this day, leading to lower returns. Information flows during trading days until Friday which is when all traders have roughly the same amount of information; hence, most informed trades occur during the last day of the week, leading to a higher expected return. Damodaran (1989) and Sias and Starks (1995) propose similar mechanisms.

Monthly seasonality in stock markets have also been researched, in particular the so-called "January" or "turn-of-the-year" effect. This phenomenon refers to the historical pattern in which stock prices rise in the first few days of January, especially for small firms as documented by Roll (1983), Keim (1983) and Lakonishok and Smidt (1988). Gultekin and Gultekin (1983) find monthly seasonality caused by higher returns on January in several stock markets, apart from the US. The most common explanation of this effects is tax-loss trading, see inter alia Porterba and Weisbenner (2001). The stock market tends to become oversold in December when investors sell underperforming stocks at year-end to claim capital losses on their tax returns; after the new tax year begins, the same investors tend to reinvest the money from those sales, making the overall market rise.

Finally, the influential work by Ariel (1987) reports a temporary increase in stock prices during the last few days and the first few days of each month, a phenomenon known as the "turn-of-the-month" effect. Jaffe and Westerfield (1989), Cadsby and Ratner (1992), Agrawal and Tandon (1994) and Kunkel et. al. (2003) provide international evidence on such effect. Since the timing of the effect seems to depend on the country analyzed, and may not coincide with that of the US stock market, it is concluded that, as in other calendar effects, the "turn-of-the-month" is not a simple spillover from the US market. The most accepted explanation, inspired 
by how the US market behaves but that often applies to markets with different institutional arrangements, is that that portfolio managers tend to improve their fund appearance before presenting them to their clients or shareholders. De Bondt and Thaler (1987) argue that such "window dressing" takes place on the days near the turning of the month.

\section{Methodological discussion}

The standard way to compute calendar effects within a regression framework is to regress historical returns on a set of event dummy variables. The way these dummies enter the regression model, i.e. how they are "coded", can affect severely the interpretation given to the associated coefficients. Next, we discuss the identification of calendar effects in this context. Then, we also brief the main methods for estimation and inference used in our empirical analysis.

\subsection{Coding the calendar effects}

Let $y_{d m}$ denote the typical observation for the daily return of a stock index on Day $=d$ in Month $=m$. The calendar effects can be modeled following the two-way ANOVA representation

$$
y_{d m}=\alpha+\delta_{d}+\mu_{m}+\varepsilon_{d m},
$$

where $\alpha$ is an intercept, $\delta_{d}$ represents the day effect, $\mu_{m}$ is the month effect and $\varepsilon_{d m}$ is a zero-mean error term. It is assumed that calendar effects in $y_{d m}$ are completely captured in $\delta_{d}$ and $\mu_{m}$. More formally, that $\varepsilon_{d m}$ is mean independent from Day and Month, $\mathrm{E}(\varepsilon \mid$ Day,Month $)=\mathrm{E}(\varepsilon)=0$. It is worth mentioning that, in practice, a more general specification for the return equation may be desirable, for instance by including dynamic terms (lags of $y$ ) or other control variables. However, for the discussion that follows, focusing on the identification of the calendar effects, the stylized representation (1) suffices with no loss of generality.

The model in (1) can be put in regression format, for a typical observation $t$, as

$$
y_{t}=\alpha+\sum_{i=1}^{n_{d}} \delta_{i} D_{i t}+\sum_{i=1}^{n_{m}} \mu_{i} M_{i t}+\varepsilon_{t}
$$

where $D_{d t}$ denotes the $d$-th day dummy variable such that $D_{d t}=1$ if Day ${ }_{t}=d$ and $D_{d t}=0$ otherwise (for $d=1,2, \ldots, n_{d}$ ), whereas $M_{m t}$ denotes the $m$-th month dummy variable defined as $M_{m t}=1$ if Month $_{t}=m$ and $M_{m t}=0$ otherwise (for $m=1,2, \ldots, n_{m}$ ). It is well known that, as it stands, equation (2) cannot be estimated due to perfect collinearity, the so-called dummy variable trap: both the $n_{d}$ day dummies and the $n_{m}$ month dummies represent all possible values of Day ${ }_{t}$ and Month ${ }_{t}$ and thus saturate the regression $\left(\sum_{i=1}^{n_{d}} D_{i t}=\sum_{i=1}^{n_{m}} M_{i t}=1\right)$.

In order to deal with the dummy variable trap, some restrictions ought to be imposed. Specifically, as many restrictions as exhaustive groups (i.e., two in our setup). The dominant approach in the literature to solve this collinearity issue, often known as dummy coding, is to drop one dummy variable from each group, and let the intercept absorb their effects (see, inter alia, Lakonishok and Smidt, 1988; Chang et. al., 1993; Kristjanpoller, 2012). This amounts to pick a reference date $\left(d^{\prime}, m^{\prime}\right)$ and set

$$
\delta_{d^{\prime}}=\mu_{m^{\prime}}=0 .
$$

Upon imposing such restrictions, (2) becomes

$$
y_{t}=\alpha+\sum_{i \neq d^{\prime}} \delta_{i} D_{i t}+\sum_{i \neq m^{\prime}} \mu_{i} M_{i t}+\varepsilon_{t}
$$


which can estimate $\alpha, \delta_{d}$ for all $d \neq d^{\prime}$ and $\mu_{m}$ for all $m \neq m^{\prime}$. From (1) and (3), it can be verified that

$$
\begin{aligned}
& \mathrm{E}\left(y \mid \text { Day }=d^{\prime}, \text { Month }=m^{\prime}\right)=\alpha \\
& \mathrm{E}\left(y \mid \text { Day }=d, \text { Month }=m^{\prime}\right)=\alpha+\delta_{d} \\
& \mathrm{E}\left(y \mid \text { Day }=d^{\prime}, \text { Month }=m\right)=\alpha+\mu_{m},
\end{aligned}
$$

which, in turn, implies that

$$
\begin{aligned}
\alpha & =\mathrm{E}\left(y \mid \text { Day }=d^{\prime}, \text { Month }=m^{\prime}\right) \\
\delta_{d} & =\mathrm{E}\left(y \mid \text { Day }=d, \text { Month }=m^{\prime}\right)-\mathrm{E}\left(y \mid \text { Day }=d^{\prime}, \text { Month }=m^{\prime}\right) \\
\mu_{m} & =\mathrm{E}\left(y \mid \text { Day }=d^{\prime}, \text { Month }=m\right)-\mathrm{E}\left(y \mid \text { Day }=d^{\prime}, \text { Month }=m^{\prime}\right) .
\end{aligned}
$$

The coefficients in (4) represent effects relative to the reference date, which consists on a day of the week and a month. For instance, $\delta_{1}$ is the effect of a Monday in (say) April relative to (say) a Wednesday in April, whereas $\mu_{1}$ is the effect of a Wednesday in January relative to a Wednesday in April. The estimation results and their interpretation are, thus, quite sensitive to the choice of $d^{\prime}$ and $m^{\prime}$, which is necessarily arbitrary. Moreover, if the group of month dummies is removed from the model, the interpretation of $\delta_{1}$ is relative to another day of the week only (say, in a "typical month"), and the resulting coefficient is not comparable to similar models that do include the monthly indicators.

A more satisfactory approach, rendering more sensible results that are considerably easier to interpret and to compare among competing models, is the so-called effect coding. Here, a reference date is also chosen (two restrictions to the regression model are still to be imposed) but instead of selecting a particular day of the week in a particular month, the reference date is an average across all possible dates. Note that, unlike the dummy coding case, this reference "average" date is unique. The two coefficient restrictions that solve the dummy variable trap are now

$$
\sum_{i=1}^{n_{d}} \delta_{i}=\sum_{i=1}^{n_{m}} \mu_{i}=0,
$$

and so the regression model becomes

$$
y_{t}=\alpha+\sum_{i \neq d^{\prime}} \delta_{i}\left(D_{i t}-D_{d^{\prime} t}\right)+\sum_{i \neq m^{\prime}} \mu_{i}\left(M_{i t}-M_{m^{\prime} t}\right)+\varepsilon_{t}
$$

Mechanically, as in the case of (4), the coefficient $\delta_{d}$ for $d \neq d^{\prime}$ accompanies a dummy variable that equals one if Day ${ }_{t}=d$. However, the dummy takes the value of zero if Day ${ }_{t}=d^{\prime}$ under dummy coding, and minus one under effect coding. This small recodification leads to a rather different interpretation of the estimated coefficients. From (1) and (7), it can be verified that

$$
\begin{array}{r}
\frac{1}{n_{m}} \sum_{i=1}^{n_{m}} \mathrm{E}(y \mid \text { Day }=d, \text { Month }=i)=\alpha+\delta_{d}, \\
\frac{1}{n_{d}} \sum_{i=1}^{n_{d}} \mathrm{E}(y \mid \text { Day }=i, \text { Month }=m)=\alpha+\mu_{m}, \\
\frac{1}{n_{d} n_{m}} \sum_{i=1}^{n_{d}} \sum_{j=1}^{n_{m}} \mathrm{E}(y \mid \text { Day }=i, \text { Month }=j)=\alpha .
\end{array}
$$

Let $z$ denote a discrete random variable taking on values $z_{1}, z_{2}, \ldots, z_{n}$. Then, the law of iterated expectations tells us that $\mathrm{E}(y)=\mathrm{E}(\mathrm{E}(y \mid z))=\sum_{i=1}^{n} \operatorname{Pr}\left(z=z_{i}\right) \mathrm{E}\left(y \mid z=z_{i}\right)$. The unconditional expectation (with respect 
to $z)$ is a weighted average of the the conditional expectations $\mathrm{E}\left(y \mid z=z_{i}\right)$, where the weights are given by the probability that $z$ takes on the value $z_{i}$. In a typical sample of daily returns, $\operatorname{Pr}(\operatorname{Day}=d)=1 / n_{d}$ for all $d$, and $\operatorname{Pr}($ Month $=m)=1 / n_{m}$ for all $m$. Therefore, the results in (9) simplify to

$$
\begin{aligned}
\mathrm{E}(y \mid \text { Day }=d) & =\alpha+\delta_{d}, \\
\mathrm{E}(y \mid \text { Month }=m) & =\alpha+\mu_{m}, \\
\mathrm{E}(y) & =\alpha .
\end{aligned}
$$

In equation (8), $\alpha$ estimates the unconditional or grand mean of $y$, whereas $\delta_{d}=\mathrm{E}(y \mid$ Day $=d)-\mathrm{E}(y)$ has the neat interpretation of being a "pure" day effect relative to this grand mean, after integrating (averaging) out any month effect. Similarly, $\mu_{m}=\mathrm{E}(y \mid$ Month $=m)-\mathrm{E}(y)$ is a pure month effect.

It is worth emphasizing that the difference between the dummy and effect coding approaches lies on the restrictions imposed in order to obtain an estimable model. In fact, the fit and residuals of regressions (4) and (8) are identical. Therefore, model adequacy and joint significance tests are of no use to discriminate between approaches. One approach is to be preferred to the other on extra-statistical grounds. We reckon that the much clearer, and more natural, interpretation of calendar effects under the effect coding scheme, which stems from the uniqueness of the reference date, should be enough justification to adopt it in practical work, as we do in our empirical section below. ${ }^{1}$

\subsection{Econometric issues}

Using standard notation, the linear regression model (8), with $T$ observations and augmented with other calendar effects and other control variables ( $K$ regressors in total), can be written as $\mathbf{y}=\mathbf{X} \boldsymbol{\beta}+\boldsymbol{\varepsilon}$, where $\mathrm{E}(\boldsymbol{\varepsilon})=\mathbf{0}$ and $\operatorname{var}(\boldsymbol{\varepsilon})=\Omega$ is a positive definite diagonal matrix $\Omega=\operatorname{diag}\left(\omega_{1}, \omega_{2}, \ldots, \omega_{T}\right)$, where $\operatorname{var}\left(\varepsilon_{t}\right)=\omega_{t}$ for $t=1,2, \ldots, T$. Under this specification, the least squares estimator $\hat{\boldsymbol{\beta}}=\left(\mathbf{X}^{\prime} \mathbf{X}\right)^{-1} \mathbf{X}^{\prime} \mathbf{y}$ is consistent.

The purpose of our study is not only to explore whether significant calendar effects can be found in the Latin American stock markets, but also to assess if these effects are robust to misspecifications of the regression equation. Thus, in our empirical exploration we perform an extreme bounds analysis (EBA), as championed by Leamer $(1983,1985)$. EBA is a robustness check that addresses model uncertainty, based on the idea that the inferences made for a regression coefficient of interest (namely, its sign and magnitude) can be sensitive to the inclusion or exclusion of other regressors. See Hlavac (2015) for a comprehensive, recent account.

EBA works as follows. In assessing whether a particular effect is robust, in the sense that it prevails regardless of the specification of the regression model, a number of regressions are estimated by varying the set of included conditioning variables in $\mathbf{X}$. Each regression produces an estimate of the effect of interest, say $\hat{\beta}$, and of its standard error, say $\hat{\sigma}$, so a confidence interval of the form $\hat{\beta} \pm \tau \hat{\sigma}$, where $\tau$ is a critical value (often $\tau=1.96)$, can be constructed. The lower extreme bound is the lowest value of $\hat{\beta}-\tau \hat{\sigma}$ among competing specifications, whereas the upper extreme bound is the largest value of $\hat{\beta}+\tau \hat{\sigma}$. The interval between the lower and upper extreme bounds represents the values that the $\beta$ coefficient could take at a given confidence level. Put it differently, standard tests would fail to reject the hypothesis that $\beta$ equals any value within the extreme bounds. Therefore, it is said that the effect is robust if the sign of both extreme bounds is the same, whereas the effect is not robust, or "fragile", if zero is contained in the extreme bounds interval.

${ }^{1}$ The coefficients $\delta_{d^{\prime}}$ and $\mu_{m^{\prime}}$ are dropped from (4) and hence need to be computed from the restrictions in (7). The effect coding approach provides also a convenient computational trick to overcome this limitation, in order to obtain a complete profile of day or month effects. Consider another base day $d^{\prime \prime} \neq d^{\prime}$. Then, it is simple to verify that

$$
\sum_{i \neq d^{\prime}} \delta_{i}\left(D_{i t}-D_{d^{\prime} t}\right)=\sum_{i \neq d^{\prime}} \delta_{i}\left(D_{i t}-D_{d^{\prime} t}\right)+\sum_{i} \delta_{i}\left(D_{d^{\prime} t}-D_{d^{\prime \prime} t}\right)=\sum_{i \neq d^{\prime \prime}} \delta_{i}\left(D_{i t}-D_{d^{\prime \prime} t}\right)
$$

This equivalence means that regardless on whether the regression uses $d^{\prime}$ or $d^{\prime \prime}$ as the base day, the estimated $\delta$ s (other than $\delta_{d^{\prime}}$ and $\left.\delta_{d^{\prime \prime}}\right)$ will be identical. Thus $\delta_{d^{\prime}}$ and its standard error can be estimated directly from the output of an auxiliary regression using $d^{\prime \prime}$ as a base day. 
EBA is regarded as a very stringent criterion for robustness (see, inter alia, Sala-i-Martin, 1997). As a result, in applications it is generally the case that most (if not all) of the candidate regression variables are declared fragile. Hence, if a variable is regarded as robust under EBA, it is quite likely that it will be cataloged as robust with other methods dealing with model uncertainty.

An important point to consider is how to estimate $\sigma$, the standard error of $\hat{\beta}$. Since we are dealing with daily financial data, we expect the error terms in our regressions to be highly heteroscedastic. If this is indeed the case, the computed conventional standard errors of estimated coefficients, that assumes homoscedasticity, may too small, and the extreme bounds may appear artificially narrower. Thus, we adjust our inferential procedures by considering corrected standard errors from the so-called HC (heteroscedasticity consistent) family (MacKinnon and White, 1985). In particular, we use the strategy advanced in Angrist and Pischke (2009, ch. 8) of estimating $\sigma$ as the maximum between the conventional and HC estimators. This results in the widest possible confidence interval for $\beta$, which from a conservative viewpoint can be considered as a better characterization of uncertainty.

To describe the $\mathrm{HC}$ estimators, define the covariance matrix estimator

$$
\operatorname{HC}(\hat{\boldsymbol{\beta}})=\left(\mathbf{X}^{\prime} \mathbf{X}\right)^{-1} \mathbf{X}^{\prime} \mathbf{A X}\left(\mathbf{X}^{\prime} \mathbf{X}\right)^{-1},
$$

where $\mathbf{A}=\operatorname{diag}\left(a_{1}, a_{2}, \ldots, a_{n}\right)$. Also, define the $t$-th regression residual $e_{t}=y_{t}-\mathbf{x}_{t}{ }^{\prime} \hat{\boldsymbol{\beta}}$, where $\mathbf{x}_{t}{ }^{\prime}$ is the $t$-th row of $\mathbf{X}$, and $h_{t}=\mathbf{x}_{t}{ }^{\prime}\left(\mathbf{X}^{\prime} \mathbf{X}\right)^{-1} \mathbf{x}_{t}$ which is the $(t, t)$-th element of the so-called "hat matrix". Different choices of $a_{t}$ render different $\mathrm{HC}$ estimators, the most popular being

$$
\text { Conventional }: a_{t}=\frac{1}{T-K} \sum_{s=1}^{T} e_{s}^{2} \text { for all } t, \quad \mathrm{HC} 1: a_{t}=\frac{T}{T-K} e_{t}^{2}, \quad \mathrm{HC} 3: a_{t}=\frac{e_{t}^{2}}{\left(1-h_{t}\right)^{2}} .
$$

HC1 incorporates a simple degrees of freedom correction to the well known White's estimator $\left(a_{t}=e_{t}^{2}\right.$, see MacKinnon and White, 1985), whereas HC3 gives an approximation, developed in Davidson and MacKinnon (1993, ch. 16), of the jackknife estimator of the variance. ${ }^{2}$ Using Monte Carlo simulations, MacKinnon and White (1985) and Long and Ervin (2000) evaluate the properties of significance tests of the regression coefficients using the conventional and $\mathrm{HC}$ estimators, and conclude that in relatively large samples, all HC estimators behave similarly. Yet, the general recommendation is to always use HC3 because it tends to keep the test size at the nominal level regardless of the presence or absence or heteroscedasticity, whereas it induces an inconsequential loss of power when the errors are indeed homoscedastic. Exact results in Cribari-Neto et. al. (2005) also point out to the superiority of HC3. We, therefore, adopt HC3 as our preferred HC estimator.

\section{Empirical analysis}

This section presents the main results of the paper. We first describe the data used in our empirical work. Then, we present results on a preliminary analysis based on simple $t$ tests comparing average returns for different events. Monday, Friday and turn-of-the-month effects appear to be significant at this stage. The regression and extreme bound analysis follows and confirms that Monday effects are robust in every case, whereas the remaining effects are, in general, robust but not as widespread. The section ends with results on the stability through time of the estimated Monday and Friday effects.

\footnotetext{
${ }^{2}$ The actual jackknife estimator of the variance measures the dispersion of the $T$ delete-one estimators (i.e., the estimators of $\boldsymbol{\beta}$ after removing one observation from the sample) around its sample average. In the HC3 estimator, the dispersion is measured around the least squares estimate. In our empirical work, the average delete-one estimates turned out to be almost identical to the least squares estimates, pointing out to negligible finite sample biases. An implication is that HC3 provides a very accurate approximation to the actual, computationally more demanding, jackknife estimator. Details on this comparison are available upon request.
} 


\subsection{Data}

The dataset consists of representative indices for the Latin American stock markets, extracted from the Bloomberg database. The data are daily and returns are measured as the percentage change of the closing value of the indices. The selected indices are: Mercado de Valores (MERVAL) for Argentina, Bolsa de Valores, Mercadorias \& Futuros de Sao Paulo (BOVEPSA) for Brazil, Indice de Precios Selectivo de Acciones (IPSA) for Chile, Indice de la Bolsa de Valores (IGBC) for Colombia, Indice de Precios y Cotizaciones (IPC) for Mexico and Indice Selectivo Bolsa de Valores de Lima (ISBVL) for Peru. As detailed below, we also use data from the US stock market as measured by the Standard \& Poor's 500 index.

With the exception of Colombia, the data spans the 20-year window from 1995 to 2014. Thus, for each country the dataset contains, after accounting for non-trading days, about 4,800 observations on returns, which correspond to nearly 960 observations for each day of the week (or 400 observations for each month of the year), and 239 turn-of-the-month and 19 turn-of-the-year episodes.

In the Colombian case, the national stock exchange started operating on July 2001, as the merger of three regional stock exchanges in Bogotá, Medellín and Occidente. Hence, the data of the IGBC runs from this date, which is also the last date indices from the individual stock exchanges (such as Bogotá's IBB) are recorded. Changes in methodology, data collection techniques and representativeness render the IGBC incomparable to the the individual indices from which data prior to July 2001 are available. Thus, we do not attempt any extrapolation of the IGBC based on the behavior of indices such as the IBB. All in all, in the Colombian case the number of observations reduces to about 3,000, with 115 turn-of-the-month and 13 turn-of-the-year episodes.

The turn-of-the-month indicator, following standard practices in the literature (cf. Kunkel et. al., 2003), is computed as a dummy variable equal to one for the last five and first five calendar days of the month. This amounts to an average of three to four trading days prior and after the change of the month. On the other hand, the turn-of-the-year indicator equals one for the days on the last and first week of the year, which amounts again to three to four trading days prior and after the change of the year.

The holiday indicator equals one on the day before and on the day after a public holiday. For each country, national holidays where identified from public sources such as timeanddate.com and from the website of each stock exchange. Public holidays are not necessarily regular, even tough they are often predictable. In Latin America, it is common for most holidays to be moveable, especially for non-religious dates. Often, if the date falls on a Tuesday or Wednesday, the holiday is the preceding Monday, whereas if it falls on a Thursday or Friday then the holiday is the following Monday. Besides, touristic holiday bridges are commonplace. Here, if a non-movable holiday falls on Tuesday or Thursday, an extra holiday is added on the previous Monday or the following Friday, respectively. Table 1 presents the base dates from which we construct our holiday indicators, which are available upon request.

It is worth mentioning that the effect coding in the turn-of-the-month, turn-of-the-year and holiday indicators is slightly different due to their unbalanced nature. If $D_{t}$ denotes one of such dummies, its effect-coded version is $D_{t}-\bar{D}\left(1-D_{t}\right) /(1-\bar{D})$, where $\bar{D}$ is the sample average of $D_{t}$, such that it averages zero. In this way, the coefficient of $D_{t}$ is still interpreted as a deviation from the grand mean, which is still estimated by the intercept.

\subsection{Preliminary analysis}

Table 2 presents prima facie evidence on the significance of some calendar effects in our sample. In particular, it compares the average return recorded on Mondays, Fridays and by the turn of the month relative to the average return from the rest of the days. The table also reports standard $t$-tests for the null hypothesis that the mean return in such episodes is equal to the mean return for the rest of the days. To save space, we do not report this comparison for other calendar effects as they were, with very few exceptions, not statistically significant. These results, however, are available upon request. 
Some effects are apparent. On average, returns on Mondays are statistically lower than returns on the rest of the days, whereas returns on Fridays appear statistically higher (with the exception of Mexico). Thus, there is a clear indication of a weekend effect in all the cases we analyze. Similarly, the average return is found to be statistically higher during the last few days and the first few days of each month, pointing out to the existence of a turn-of-the-month effect.

Even though indicative, the results in Table 2 are not necessarily conclusive. The $t$-tests do allow for some heteroscedasticity (variances are allowed to differ between events), but fail to account for other distorting factors as serial correlation and from the influence of conditioning variables. Furthermore, even though they do provide an assessment of the uncertainty brought the sampling variability, they ignore the relevant source of model uncertainty. All these difficulties can be easily dealt with in the regression analysis that follows.

\subsection{Regression analysis}

Next, we enquire whether the effects found in our preliminary exploration are robust, and remain valid after a thorough sensitivity analysis. Hence, we now implement the framework discussed in section 3.2.

The basic specification includes a constant term to estimate the grand mean, a full set of effect-coded day dummy variables and the first lag of the stock index return. In a preliminary exploration, a small amount of serial correlation was found in the regression residuals, even after controlling for other factors. The inclusion of the first lag as a explanatory variable seemed to be enough to guarantee serially uncorrelated residuals. The lag enters as a deviation from its sample average, to prevent the dynamic term from altering the magnitude of the calendar effects.

We entertain augmenting this basic specification with other calendar effects that have been considered in the literature (cf. Thaler, 1987; Agrawal and Tandon, 1994) Namely, effect-coded month dummy variables (12 categories) and fortnight dummy variables ( 2 categories). This may enter either separately or interacted in a set of month-fortnight dummy variables (24 categories). Furthermore, turn-of-the-month, turn-of-the-year and holiday dummies.

Given that stock markets are tightly interconnected and that information flows rapidly from one market to the other, one may enquire whether the calendar effects found in Latin American stock markets, if any, reflect autonomous phenomena or are a simple manifestation of the widely documented calendar effects in industrialized economies. To take this possibility into account, we also consider as a control variable the returns of the US stock market (deviated from its sample average), admittedly the foreign market which influences Latin American markets the most. The calendar effects found after controlling for the behavior of the US stock market can be, therefore, regarded as legitimate.

All in all, for each country in our sample, the extreme bounds analysis is based on the results of 20 regressions, beginning with the basic specification with $K=6$ regressors described above, and ending with a full specification that includes $K=33$ regressors. The list of equations is the following: first, (i) the basic model, (ii) the basic model augmented with the "other" calendar effects (turn-of-the month, turn-of-the-year and holiday dummies, $K=9$ ), (iii) the basic model augment with the US returns $(K=7)$, (iv) the basic model augmented with the "other" calendar effects and the US return $(K=10)$; then, these 4 specifications are further augmented with the month dummies group (4 additional models, with $K$ ranging from 17 to 21 ), with the fortnight dummies group (4 additional models, with $K$ ranging from 7 to 11), with both (4 additional models, with $K$ ranging from 18 to 22 ) and with the month-fortnight interactions (the 4 final models, with $K$ ranging from 29 to 33 ).

Table 3 presents selected results from this analysis. For the sake of brevity, only the output of the basic and full models is reported, along with the extreme bounds from all models. The intermediate models (available upon request) largely confirm the main conclusions of this table. Also, very few month and fortnight effects were found statistical significant across regressions and, correspondingly, were dubbed as fragile by their extreme bounds. To avoid clutter, we do not report results on these estimates even though they are included as controls in the full model. 
With no surprise, the returns on the US stock market $\left(y_{t}^{*}\right)$ are found to be statistically significant across regressions, and thus regarded as robust by the extreme bounds. With the exception of Brazil, the same is true for the lagged return $\left(y_{t-1}\right)$. It is interesting to note that in all instances the sum of the coefficients of $y_{t}^{*}$ and $y_{t-1}$ is, statistically speaking, not different from one. Thus, the estimated equations can be written as $y_{t}=(1-\rho) y_{t-1}+\rho y_{t}^{*}+\mu_{t}$, where $\mu_{t}$ encompasses all other factors determining $y_{t}$. Since $\rho>0$, we can write $\Delta y_{t}=-\rho\left(y_{t-1}-y_{t}^{*}\right)+\mu_{t}$ and conclude that $y_{t}$ error corrects towards $y_{t}^{*}$. Latin American markets follow closely the US market. Alternatively, the estimated equations can be thought of as $y_{t}-y_{t}^{*}=(1-\rho)\left(y_{t-1}-y_{t}^{*}\right)+\mu_{t}$ which is an equation of the excess return relative to the US. This formulation is a generalization of the way Agrawal and Tandon (1994) control for the effect of the US market (which implicitly assume $\rho=1$ ), after correcting for serial correlation.

Even after controlling for the US returns, weekend effects are found to be a robust feature of the data. In all cases, the returns on Mondays are significantly lower than on the average date. The point estimates range narrowly from -0.10 to -0.20 percent. Besides, the Monday effect is compensated by a Friday effect: returns are significantly higher, and of comparable magnitude than on Monday, on Fridays. The remarkable exception is Mexico, where we found no evidence that returns on Fridays are different from the average date. No other day of the week exhibits a significant effect.

On the other hand, the turn-of-the-month effect, that appeared significant in Table 2 for all countries but Argentina, ceased to be important in the case of Brazil. For the remaining 4 countries, this effect is robust, with a magnitude of something less than 0.10 percent. No other calendar effect was found robust.

\subsection{Subsample stability}

It is worth asking whether the Monday and Friday effects found, which are robust to model specification, are also robust to the sample used in the estimation. Specifically, whether these effects are stable through time. Besides the fact that parameter stability is an indication of correct model specification, answering this question can be viewed as an indirect test of whether information and transaction costs matter for the determination of these calendar effects. Such costs must have reduced substantially in our sample, given the explosive growth in the usage of internet and other information technologies, and the automation of stock market operations worldwide since the mid 1990s. Furthermore, as argued by Schwert (2003), calendar effects may be arbitraged away as they become increasingly known to market participants.

To investigate these possibilities within the scope of our sample, we perform the following recursive estimation exercise. A first set of regressions is run from 1994 to the end of 2000. This amounts to one third of the full sample (roughly, 1,600 observations and 320 Mondays and Fridays). Then, the regressions are estimated again after adding one month worth of daily data at a time, until the full sample is reached. At each iteration, the average estimate and the extreme bounds are stored. In the case of Colombia, the first third of the sample ends in 2006 (about 1,000 observations and 320 Mondays and Fridays).

The results are displayed in Figure 1, where the Monday effects are negative and the Friday effects are positive. These effects are remarkably stable through time. The full sample conclusions from Table 3 (robust effects in all countries but in Mexico, where the Friday effect is not significant) hold in almost every estimation involved in the recursive exercise. Very few exceptions are recorded in the Argentinean case at the first subsamples, where the extreme bounds slightly cross (albeit unfrequently) zero.

In some instances, remarkably the Brazilian, the time path of the estimated effects seems to be sloping either upwards (Monday) or downwards (Friday). Nonetheless, formal testing procedures would not reject the hypothesis of subsample stability. Visually, in all cases the point estimates of the effects at time $t_{1}$ lie between the bounds computed at time $t_{0} \neq t_{1}$. 


\section{Concluding remarks}

In this paper, we examine stock market returns in six major Latin American countries for the presence of calendar effects that have been documented in developed countries and other emerging markets. We find that Monday returns are the lowest and negative in all six markets, whereas Friday returns are the highest and positive in five cases. These findings are consistent with what is found in other countries, remarkably the US. Similarly, we also find evidence of an important turn-of-the-month effect in four cases, where we observe large positive returns over the few days before and after the turn of the month. This result is also documented for more developed markets. It is important to emphasize that such effects are present in the data even after controlling for the US returns; in that sense, they cannot be regarded as spillovers from advanced markets but as autonomous phenomena.

Our findings are robust to model misspecification and appear to be stable through time. The extreme bound analysis that we have adopted suitably inflates the appropriate confidence intervals to account for model uncertainty. Remarkably, these results come from a relatively unexplored dataset, and so our empirical exploration is not distorted by "data mining" biases. Having found important calendar effects in Latin American, we believe, can be seen as supporting evidence that such effects are not artifacts but true patterns in the data. This conclusion points out to the need to refine existing theories and to explore alternatives explanations for the calendar effects. The various theories entertained in the literature may be valid for developed markets, but may not be completely adequate for emerging markets such as Latin America's.

Finally, when measuring the calendar effects within a regression framework, we have proposed to set the reference date to an average date, which can be easily implemented by recoding the event dummy variables of interest that enter as explanatory variables. We reckon this is a natural way to proceed, rendering neat effects to interpret. Despite that this minor technicality can have profound effects on the interpretation of the estimated calendar effects, it has been overlooked by the literature. By pointing this issue out, we hope future research to give it its deserved importance, in order to have more comparable results among studies.

\section{References}

Agrawal, A. and K. Tandon (1994), "Anomalies or illusions? Evidence from stock markets in eighteen countries", Journal of International Money and Finance, 13(1), 83-106

Angrist, J. D. and J. S. Pischke (2009), Mostly Harmless Econometrics: An Empiricist's Companion, Princenton University Press.

Ariel, R. A. (1987), “A monthly effect in stock returns", Journal of Financial Economics, 18(1), 161-174.

Cadsby, C. B. and M. Ratner (1992) "Turn-of-month and pre-holiday effects on stock returns: Some international evidence", Journal of Banking and Finance, 16(3), 497-509.

Chang, E. C., J. M. Pinegar and R. Ravichandran (1993), "International evidence on the robustness of the day-of-the-week effect", Journal of Financial and Quantitative Analysis, 28(4), 497-513.

Connolly, R. (1989), "An examination of the robustness of the weekend effect", Journal of Financial and Quantitative Analysis, 24(2), 133- 169.

Cribari-Neto, F., S. L. P. Ferrari and W. A. S. C. Oliveira (2005), "Numerical evaluation of tests based on different heteroskedasticity-consistent covariance matrix estimators", Journal of Statistical Computation and Simulation, 75(8), 611-628.

Damodaran, A. (1989), "The weekend effect in information releases: A study of earnings and dividend announcements", Review of Financial Studies, 2(4), 607-623. 
Davidson, R. and J. G. MacKinnon (1993), Estimation and Inference in Econometrics, Oxford University Press.

De Bondt, W. F. M. and R. H. Thaler (1987), "Further evidence on investors overreaction and stock market seasonality", Journal of Finance, 42(3), 557-580.

Dicle, M. F. and J. Levendis (2014), "The day-of-the-week effect revisited: International evidence", Journal of Economics and Finance, 38(3), 407-437.

Foster, F. D. and S. Viswanathan (1990), "A theory of the interday variations in volume, variance, and trading costs in securities markets", Review of Financial Studies, 3(4), 593-624.

French, K. R. (1980), "Stock returns and the weekend effect", Journal of Financial Economics, 8(1), 59-69.

Gibbons, M. R. and P. Hess (1981), "Day of the week effects and asset returns", Journal of Business, 54(4), 579-596.

Gultekin, M. N. and N. B. Gultekin (1983), “Stock market seasonality: International evidence”, Journal of Financial Economics, 12(4), 469-481.

Keim, D. B. (1983), "Size-related anomalies and stock return seasonality: Further empirical evidence", Journal of Financial Economics, 12(1), 13-32.

Keim, D. B. and R. Stambaugh (1984), "A further investigation of the weekend effect in stock returns", Journal of Finance, 39(3), 819-835.

Kiymaz, H. and H. Berument (2003), "The day of the week effect on stock market volatility and volume: International evidence", Review of Financial Economics, 12(4), 363-380.

Kunkel, R. A, W. S. Compton and S. Beyer (2003), “"The turn-of-the-month effect still lives: The international evidence", International Review of Financial Analysis, 12(2), 207-221.

Kristjanpoller, W. (2012), "Day of the week effect in Latin American stock markets", Revista de Análisis Económico - Economic Analysis Review, 27(1), 71-89.

Hlavac, M. (2015), "ExtremeBounds: Extreme Bounds Analysis in R", R package version 0.1.5, http: //CRAN.R-project.org/package=ExtremeBounds.

Jaffe, J. and R. Westerfield (1985), "The week-end effect in common stock returns: The international evidence", Journal of Finance, 40(2), 433-454.

Jaffe, J. and R. Westerfield (1989), "Is there a monthly effect in stock market returns?: Evidence from foreign countries", Journal of Banking and Finance, 13(2), 237-244.

Lakonishok, J. and M. Levi (1982), "Weekend effects on stock returns: A note”, Journal of Finance, 37(3), 883-889.

Lakonishok, J. and S. Smidt (1988), "Are seasonal anomalies real? A ninety-year perspective", Review of Financial Studies, 1(4), 403-425.

Leamer, E. E. (1983), "Let's take the con out of econometrics", American Economic Review, 73(1), 31-43.

Leamer, E. E. (1985), “Sensitivity analyses would help”, American Economic Review, 75(3), 308-313.

Long, J. S. and L. H. Ervin (2000), "Using heterocedasticity consistent standard errors in the linear regression model", The American Statistician, 54(3), 217-224.

MacKinnon, J. G. and H. White (1985), "Some heteroskedasticity-consistent covariance matrix estimators with improved finite sample properties", Journal of Econometrics, 29(3), 305-325. 
Porterba, J. M. and S. J. Weisbenner (2001), "Capital gains tax rules, tax-loss trading, and turn-of-the-year returns", Journal of Finance, 56(1), 353-368.

Roll, R. (1983), "Vas ist das? The turn-of-the-year effect and the return premia of small firms", Journal of Portfolio Management, 9(2), 18-28.

Sala-i-Martin, X. (1997), "I just ran two million regressions", American Economic Review, 87(2), 178-183.

Schwert, G. W. (2003), "Anomalies and market efficiency", in Constantinides, G. M., M. Harris and R. M. Stulz (eds.), Handbook of the Economics of Finance, Elsevier, vol 1, ch 15, 939-974.

Sias, R. W. and L. T. Starks (1995), "The day-of-the-week anomaly: The role of institutional investors", Financial Analysts Journal, 51(3), 58-67.

Sullivan, R., A. Timmermann and H. White (2001), "Dangers of data mining: The case of calendar effects in stock returns", Journal of Econometrics, 105(1), 249-286.

Thaler, R. H. (1987), "Anomalies: Weekend, holiday, turn of the month, and intraday effects", Journal of Economic Perspectives, 1(2), 169-177. 
Table 1. Public holidays in Latin American countries

\begin{tabular}{|c|c|}
\hline Common & $\begin{array}{l}\text { New Year's Day (Jan 1), Maundy Thursday, Good Friday, Labor Day (May 1), Feast of the } \\
\text { Immaculate Conception (Dec } 8 \text {, not in Brazil), Christmas Day (Dec 25). }\end{array}$ \\
\hline Argentina & $\begin{array}{l}\text { Memorial Day (Mar 24), Day of the Veterans (Apr 2), } 1810 \text { May Revolution (May 25), Flag Day } \\
\text { (Jun 20), Independence Day (Jul 9), San Martín's Day (3rd Monday of August), Day of Cultural } \\
\text { Diversity (Oct 12), National Sovereignty Day (Nov 20). }\end{array}$ \\
\hline Brazil & $\begin{array}{l}\text { Carnival (various days, beginning of Lent), Tiradentes' Day (Apr 21), Independence Day (Sep 7), } \\
\text { Our Lady of Aparecida (Oct 12), All Souls Day (Nov 2), Republic Day (Nov 15). }\end{array}$ \\
\hline Chile & $\begin{array}{l}\text { Navy Day (May 21), Feast of St Peter and St Paul (Jun 29), Our Lady of Mount Carmel (Jul 16), } \\
\text { Assumption of Mary (Aug 15), National Day (Sep 18), Army Day (Sep 19), Columbus Day (Oct } \\
\text { 12), Reformation Day (Oct 31), All Saints Day (Nov 1). }\end{array}$ \\
\hline Colombia & $\begin{array}{l}\text { Epiphany (Jan 12), Saint Joseph's Day (Mar 23), Ascension Day ( } 39 \text { days after Easter), Corpus } \\
\text { Christi (60 days after Easter), Sacred Heart ( } 68 \text { days after Easter), Feast of St Peter and St Paul (Jun } \\
\text { 29), Independence Day (Jul 20), Battle of Boyacá (Aug 7), Assumption of Mary (Aug 17), Columbus } \\
\text { Day (Oct 12), All Saints Day (Nov 1), Independence of Cartagena (Nov 11). }\end{array}$ \\
\hline Mexico & $\begin{array}{l}\text { Constitution Day (1st Monday of February), Benito Juárez's Day (3rd Monday of March), } \\
\text { Independence Day (Sep 16), Revolution Day (3rd Monday of November). }\end{array}$ \\
\hline Peru & $\begin{array}{l}\text { Feast of St Peter and St Paul (Jun 29), Independence Day (Jul } 28 \text { and 29), Feast of St Rose of Lima } \\
\text { (Aug 30), Battle of Angamos (Oct 8), All Saints Day (Nov 1). }\end{array}$ \\
\hline
\end{tabular}

Table 2. $t$ tests for selected calendar effects

\begin{tabular}{|c|c|c|c|c|c|c|c|c|}
\hline \multirow[b]{2}{*}{ Argentina } & \multirow[b]{2}{*}{ Monday } & \multirow{2}{*}{$\begin{array}{r}m_{1} \\
0.059\end{array}$} & \multirow{2}{*}{$\frac{s_{1}}{(0.081)}$} & \multirow{2}{*}{$\begin{array}{r}m_{0} \\
0.108\end{array}$} & \multirow{2}{*}{$\frac{s_{0}}{(0.034)}$} & \multirow{2}{*}{$\begin{array}{r}t \text {-statistic } \\
-1.899\end{array}$} & \multicolumn{2}{|c|}{$p$-value } \\
\hline & & & & & & & 0.058 & * \\
\hline & Friday & 0.200 & $(0.066)$ & 0.044 & (0.036) & 2.062 & 0.039 & ** \\
\hline & Turn-Month & 0.153 & $(0.057)$ & 0.042 & (0.038) & 1.614 & 0.107 & \\
\hline \multirow[t]{3}{*}{ Brazil } & Monday & -0.091 & $(0.073)$ & 0.102 & $(0.036)$ & -2.374 & 0.018 & ** \\
\hline & Friday & 0.226 & $(0.076)$ & 0.024 & $(0.036)$ & 2.391 & 0.017 & ** \\
\hline & Turn-Month & 0.169 & $(0.057)$ & 0.018 & (0.039) & 2.175 & 0.030 & ** \\
\hline \multirow[t]{3}{*}{ Chile } & Monday & -0.148 & $(0.040)$ & 0.074 & $(0.018)$ & -5.104 & 0.000 & *** \\
\hline & Friday & 0.168 & $(0.033)$ & -0.003 & (0.018) & 4.486 & 0.000 & *** \\
\hline & Turn-Month & 0.089 & (0.029) & 0.006 & $(0.020)$ & 2.405 & 0.016 & ** \\
\hline \multirow[t]{3}{*}{ Colombia } & Monday & -0.074 & $(0.058)$ & 0.130 & $(0.026)$ & -3.216 & 0.001 & *** \\
\hline & Friday & 0.249 & (0.049) & 0.052 & $(0.027)$ & 3.502 & 0.000 & *** \\
\hline & Turn-Month & 0.173 & (0.037) & 0.058 & $(0.030)$ & 2.395 & 0.017 & ** \\
\hline \multirow[t]{3}{*}{ Mexico } & Monday & -0.036 & $(0.053)$ & 0.089 & $(0.024)$ & -2.155 & 0.031 & ** \\
\hline & Friday & 0.077 & $(0.043)$ & 0.061 & $(0.025)$ & 0.314 & 0.753 & \\
\hline & Turn-Month & 0.187 & $(0.041)$ & 0.010 & $(0.026)$ & 3.664 & 0.000 & $* * *$ \\
\hline
\end{tabular}

Notes: $m_{1}$ is the sample average for observations in the selected event (Monday, Friday or Turn-of-the-month) whereas $m_{0}$ is the sample average for the rest of the sample; $s_{i}$ is the estimated standard error of $m_{i}(i=0,1)$. The $t$-statistic is $t=\left(m_{1}-m_{0}\right) / s$, where $s^{2}=s_{1}^{2}+s_{0}^{2}$ and is asymptotically distributed as a standard normal variate. ${ }^{*}[*]\{* * *\}$ indicates statistical significance of the difference in means at a $10 \%[5 \%]\{1 \%\}$ confidence level. 
Table 3. Selected estimation results and extreme bounds

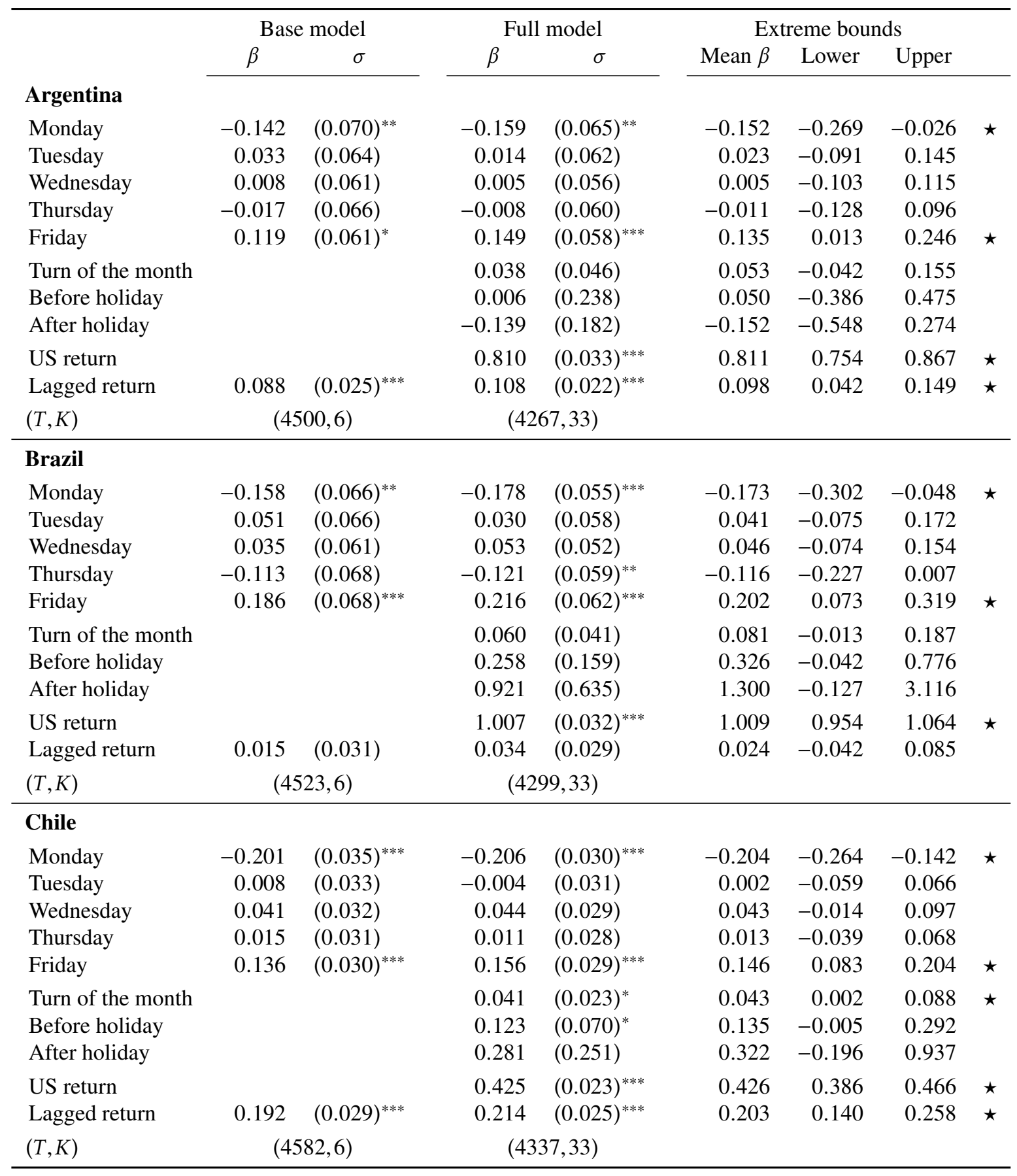

Notes: Least squares estimation. Coefficient estimates $\beta$ and HC3 standard errors $\sigma$ in parentheses. ${ }^{*}[* *]\{* *\}$ indicates statistical significance at a $10 \%[5 \%]\{1 \%\}$ confidence level. $T$ denotes the number of observations and $K$, the number of regressors. The full model includes a set of 24 month-fortnight dummies (estimates not reported). The lower [upper] extreme bounds are computed as the minimum [maximum] lower [upper] 95\% confidence limit among 20 alternative regression models, using both HC3 and conventional (homoscedastic) standard errors. $\star$ indicates a robust coefficient (i.e., the lower and upper extreme bounds have the same sign).

Continues next page. 
Table 3 (cont'). Selected estimation results and extreme bounds

\begin{tabular}{|c|c|c|c|c|c|c|c|c|}
\hline \multirow{3}{*}{ Colombia } & \multicolumn{2}{|c|}{ Base model } & \multicolumn{2}{|c|}{ Full model } & \multicolumn{3}{|c|}{ Extreme bounds } & \\
\hline & \multirow[t]{2}{*}{$\beta$} & \multirow[t]{2}{*}{$\sigma$} & \multirow[t]{2}{*}{$\beta$} & \multirow[t]{2}{*}{$\sigma$} & \multirow[t]{2}{*}{ Mean $\beta$} & \multirow[t]{2}{*}{ Lower } & \multicolumn{2}{|l|}{ Upper } \\
\hline & & & & & & & & \\
\hline Monday & -0.204 & $(0.050)^{* * *}$ & -0.204 & $(0.050)^{* * *}$ & -0.205 & -0.292 & -0.119 & $\star$ \\
\hline Tuesday & -0.047 & $(0.050)$ & -0.087 & $(0.052)^{*}$ & -0.068 & -0.175 & 0.036 & \\
\hline Wednesday & 0.082 & $(0.048)^{*}$ & 0.074 & $(0.047)$ & 0.078 & -0.006 & 0.164 & \\
\hline Thursday & 0.014 & $(0.048)$ & 0.028 & $(0.048)$ & 0.022 & -0.066 & 0.108 & \\
\hline Friday & 0.156 & $(0.046)^{* * *}$ & 0.189 & $(0.047)^{* * *}$ & 0.173 & 0.079 & 0.268 & $\star$ \\
\hline Turn of the month & & & 0.067 & $(0.034)^{*}$ & 0.071 & 0.004 & 0.141 & $\star$ \\
\hline Before holiday & & & 0.013 & $(0.138)$ & 0.020 & -0.303 & 0.332 & \\
\hline After holiday & & & 0.151 & $(0.200)$ & 0.160 & -0.229 & 0.551 & \\
\hline US return & & & 0.290 & $(0.022)^{* * *}$ & 0.291 & 0.253 & 0.329 & $\star$ \\
\hline Lagged return & & & 0.202 & $(0.046)^{* * *}$ & 0.206 & 0.125 & 0.287 & $\star$ \\
\hline$(T, K)$ & \multicolumn{2}{|c|}{$(2884,6)$} & \multicolumn{2}{|c|}{$(2726,33)$} & & & & \\
\hline \multicolumn{9}{|l|}{ Mexico } \\
\hline Monday & -0.100 & $(0.047)^{* *}$ & -0.127 & $(0.037)^{* * *}$ & -0.114 & -0.188 & -0.022 & $\star$ \\
\hline Tuesday & 0.039 & $(0.046)$ & 0.051 & $(0.038)$ & 0.046 & -0.039 & 0.120 & \\
\hline Wednesday & 0.052 & $(0.043)$ & 0.043 & $(0.035)$ & 0.048 & -0.021 & 0.127 & \\
\hline Thursday & -0.004 & $(0.044)$ & -0.002 & $(0.035)$ & -0.004 & -0.079 & 0.070 & \\
\hline Friday & 0.013 & $(0.040)$ & 0.035 & $(0.033)$ & 0.023 & -0.061 & 0.093 & \\
\hline Turn of the month & & & 0.088 & $(0.028)^{* * *}$ & 0.102 & 0.042 & 0.175 & $\star$ \\
\hline Before holiday & & & 0.073 & $(0.198)$ & 0.010 & -0.473 & 0.411 & \\
\hline After holiday & & & 0.205 & $(0.204)$ & 0.109 & -0.506 & 0.597 & \\
\hline US return & & & 0.779 & $(0.022)^{* * *}$ & 0.779 & 0.742 & 0.816 & $\star$ \\
\hline Lagged return & 0.096 & $(0.027)^{* * *}$ & 0.112 & $(0.023)^{* * *}$ & 0.103 & 0.043 & 0.154 & $\star$ \\
\hline$(T, K)$ & & $99,6)$ & $(44$ & $6,33)$ & & & & \\
\hline \multicolumn{9}{|l|}{ Peru } \\
\hline Monday & -0.166 & $(0.053)^{* * *}$ & -0.152 & $(0.050)^{* * *}$ & -0.158 & -0.253 & -0.069 & $\star$ \\
\hline Tuesday & -0.020 & $(0.046)$ & -0.060 & $(0.046)$ & -0.040 & -0.137 & 0.057 & \\
\hline Wednesday & -0.001 & $(0.046)$ & 0.010 & $(0.044)$ & 0.005 & -0.081 & 0.087 & \\
\hline Thursday & -0.004 & $(0.046)$ & -0.004 & $(0.044)$ & -0.005 & -0.081 & 0.074 & \\
\hline Friday & 0.191 & $(0.043)^{* * *}$ & 0.206 & $(0.042)^{* * *}$ & 0.198 & 0.113 & 0.279 & $\star$ \\
\hline Turn of the month & & & 0.072 & $(0.037)^{*}$ & 0.077 & 0.011 & 0.144 & $\star$ \\
\hline Before holiday & & & 0.119 & $(0.108)$ & 0.073 & -0.209 & 0.344 & \\
\hline After holiday & & & -0.147 & $(0.281)$ & -0.220 & -0.841 & 0.416 & \\
\hline US return & & & 0.505 & $(0.035)^{* * *}$ & 0.505 & 0.447 & 0.562 & $\star$ \\
\hline Lagged return & 0.145 & $(0.037)^{* * *}$ & 0.183 & $(0.032)^{* * *}$ & 0.164 & 0.079 & 0.241 & $\star$ \\
\hline$(T, K)$ & \multicolumn{2}{|c|}{$(4637,6)$} & \multicolumn{2}{|c|}{$(4394,33)$} & & & & \\
\hline
\end{tabular}

Notes: Least squares estimation. Coefficient estimates $\beta$ and HC3 standard errors $\sigma$ in parentheses. * [**] $\{* * *\}$ indicates statistical significance at a $10 \%[5 \%]\{1 \%\}$ confidence level. $T$ denotes the number of observations and $K$, the number of regressors. The full model includes a set of 24 month-fortnight dummies (estimates not reported). The lower [upper] extreme bounds are computed as the minimum [maximum] lower [upper] 95\% confidence limit among 20 alternative regression models, using both HC 3 and conventional (homoscedastic) standard errors. $\star$ indicates a robust coefficient (i.e., the lower and upper extreme bounds have the same sign).

End of table. 
Figure 1. Recursive estimation of the Monday and Friday effects

Argentina

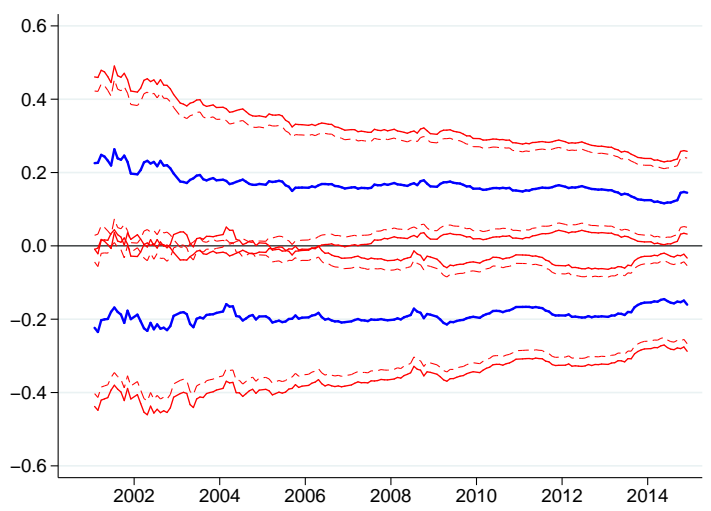

Chile

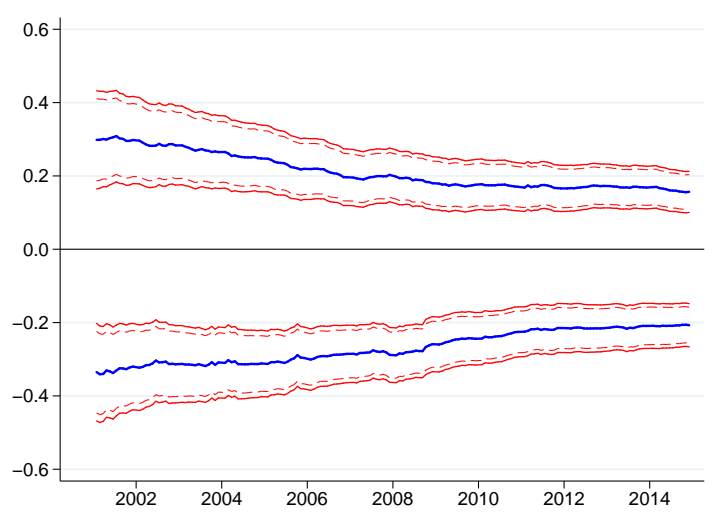

Mexico

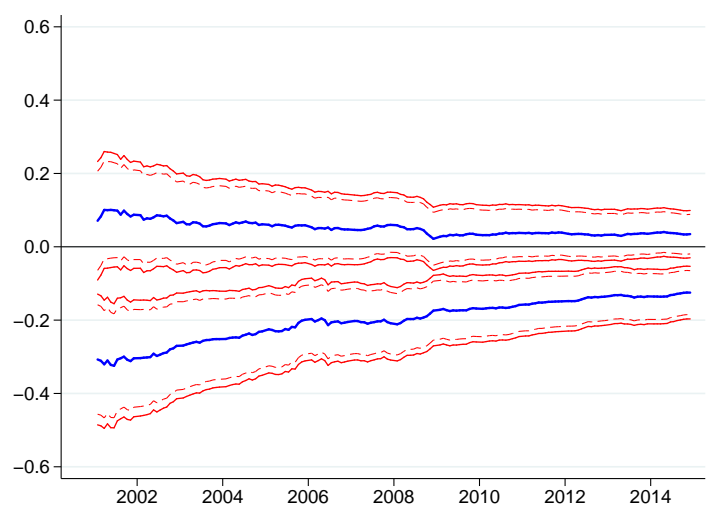

Brazil

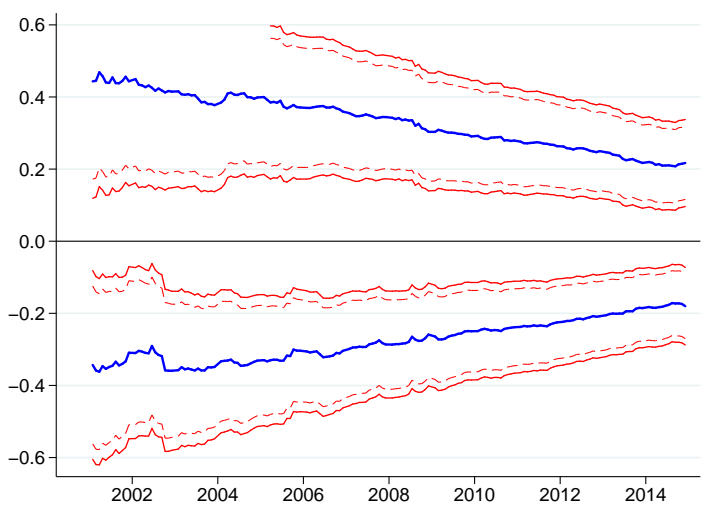

Colombia

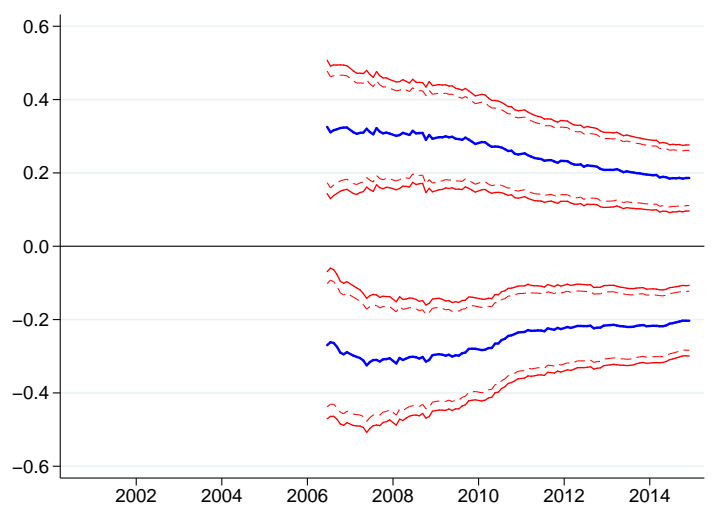

Peru

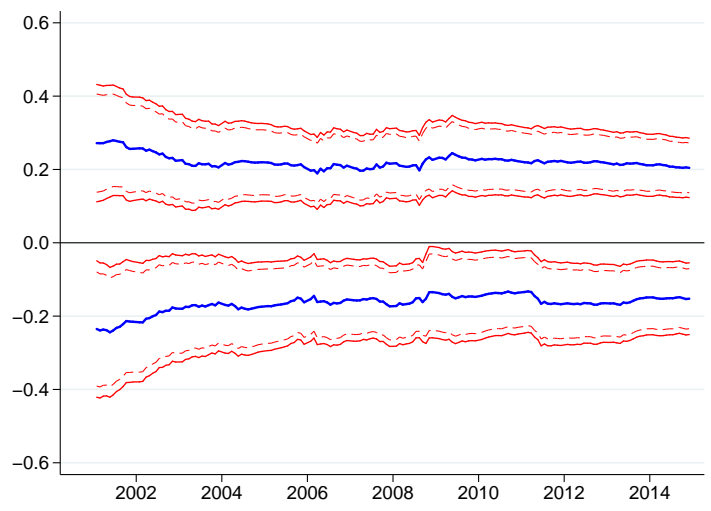

Notes: Recursive least squares estimation. Beginning with the first third of the sample, the regressions are estimated sequentially, by adding a month of data at a time. The horizontal axis shows the end of each subsample. The solid line shows the average effect among 20 competing specifications, and the dashed lines are the $90 \%$ and $95 \%$ extreme bounds. Monday effects are negative, Friday effects are positive. 